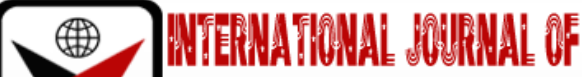

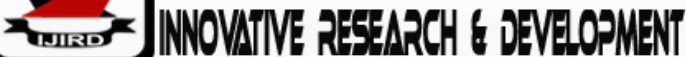

ISSN 2278 - 0211 (Online)

\section{Beijing Platform for Action: Critical Milestones to Eradication of Barriers to Women Participation in Decision Making in Kenya}

\begin{tabular}{|c|}
\hline Clinton Sukuru \\
Post-graduate Student, Department of Education Management, Policy and Curriculum Studies, \\
Kenyatta University, Kenya \\
Dr. Kiende Hellen \\
Lecturer, Department of Education Management, Policy and Curriculum Studies, \\
Kenyatta University, Kenya
\end{tabular}

\begin{abstract}
:
Women empowerment has attracted the attention of scholars globally. This is because women are a quality human resource that can change the quality of society. It is critical to note that, according to gender policy in Education there is consensus that girls and women empowerment in general has been affected by policies that manifest negatively on women access to opportunities. The purpose of this paper was to establish whether the Beijing Platform for Action declarations have been implemented to eradicate the barriers to equal participation of women as compared to men in all the sectors. The paper was guided by the following objectives: To analyze the progress made by women in power and decision making after the conference and determine the barriers that have hindered women from attaining key positions in decision making. Several international conventions and treaties ratified by member states have resulted to realization of women empowerment globally and among them is the Beijing platform of Action that was adopted by the Fourth World conference on women held at Beijing in1995. This was an agenda for women advancement and empowerment because it advocated for the removal of all the barriers to women active engagement in all spheres of life. The conference advocated for empowering women anywhere and everywhere across the globe. The implication of this empowerment would be women visibility in power and decision making. This paper was a desktop review. This review established that a significant number of women in Kenya have been able to overcome the barriers and have found their way into decision making positions. This has enhanced their participation in political, social and economic development of the country.
\end{abstract}

Keywords: Empowerment, barriers, milestones, visibility, decision making, participation

\section{Introduction}

The last two decades in the world have witnessed tremendous efforts in both women empowerment and their participation in governance and leadership spaces (Oyowa, 2015). There are numerous international conferences, treaties and documents that have focused on gender equality and women empowerment. This includes but not limited to the Beijing, 1995, SDGs, MDGs, Convention on the Elimination of All Discrimination against Women (CEDAW).All these convections have addressed the plight of women globally because their visibility has remained significantly low in most of the sectors globally which is an indication of their disempowerment (Jones, 2004).In the global arena, the emphasis is that achieving the goal of equal participation of women and men in leadership and decision-making provides a balanced development framework and more accurately reflects the composition of society; strengthens democracy and promotes proper functioning of systems and structures. In this sense, women's equal participation in governance and decisionmaking is not only a demand for justice, but also a necessary condition for gender equality and making sure that the present institutional culture is deconstructed to take women's interests into account, Oyowa, 2015.This concurs with an observation made by Lennart, 2017, the Kenyan Country Director of Plan International who observed that it is important to unlock the power of girls through making education accessible to them. Lennart further notes that Plan International was keen to empower girls to lead through 'Takeovers'. This was a concept by Plan International in 2016 to support young women or girls to takeover leadership roles in political, economic and social spaces, Daily Nation, 11th October 2017.This plan is seen to be fruitful in the increasing evidence of more women involvement in decision making globally.

The focus of this paper was on the Beijing platform for action which was held in China in 1995 and was attended by over 17,000 delegates. The magnitude of the conference was an indication that countries attached a lot of value to inclusivity of women in all aspects of societal growth. The conference was attended by over 189 governments and 30,000 activists. This was an historic event that attracted diverse representation from around the globe but all the participants had one single purpose of gender equality and empowerment of women everywhere. 
This was the most progressive blueprint ever for advancing women's rights. Various governments of the world have used this conference as a gauge for their progress as far as women empowerment and involvement in decision making is concerned.

\section{Objectives}

This paper was thus guided by the following main Objectives:

- To recognize the critical areas of concern emphasized at the conference.

- To define the highlights comprehended in the enablement of women in power and decision making.

- To understand the barriers to women participation in power and decision making in Kenya.

\section{Critical Areas Highlighted at Beijing Conference}

This platform promotes equality of rights. Political will and worldwide visibility have been unleashed by the Beijing process. Many women and girls have been protected by laws against gender-based violence in political sector (Schlesinger and Weigelt, 2012). From a socio-cultural perspective, gender is a system of power relations (Martinez, 2010). This is pre-dominant globally where patriarchal mindset is present (Jones, 2004). According to Robinson, gender discrimination is present in the social fabric $(2014$, p. 560).This was due to realization that women advancement and progression had been affected by historical injustices that bedeviled them since time immemorial. A critical look at the areas of focus of the conference reveals countries were interested in addressing the areas that derail women participation in social economic development. The platform for Action envisioned a situation where each woman and girl will exercise her freedoms and choices and unlock her full potential without any discrimination. The implication would be full participation of women in decision making which has not been realized in most of the countries globally. However, the main focus of this paper focused on Women empowerment and women in power and decision making. This is because women comprise more than half of the world population and their lack of involvement could leave out a critical mass of skills and competencies (Kibutha 2012). This would also mean that the expertise and insight of half the population is left untapped. This has far-reaching implications not only on education systems, but the status of women, and society at large.

More women at this point in time than at any previous point in time serve in political offices, are protected by laws against gender-based violence, and live under constitutions guaranteeing gender equality. For example, the Kenyan Constitution promulgated in 2010 underscores that not more than any gender would occupy appointive and elective positions in any sector, Kenyan constitution, 2010. This resonates well with a report by ILLP-UNESCO, 2017 that emphasizes that it is everybody's responsibility to promote gender equality.

It is important to note that the Platform for Action envisioned gender equality in all dimensions of life but interestingly twenty years down the line no country has actualized this agenda. Women earn less than men and are more likely to work in poor-quality jobs. A third suffers physical or sexual violence in their lifetime. Gender based violence is a criminal offence since it attacks the female workforce that hinders their productivity in various work places. The Beijing Platform for Action opens new opportunities to reconnect, regenerate commitment, charge up political will and mobilize the public and apparently it is every person's responsibility. It is indeed the yardstick which governments are using to measure women participation.

This paper urges that Women's empowerment and their full participation on the basis of equality in all spheres of society, including participation in the decision-making process and access to power, are fundamental for the achievement of equality, development and peace; In all these education plays a significant role of eradicating the sticky floor syndrome which affects most women and providing better avenues of breaking the glass ceiling barriers. This occurs amidst a historical scenario where women access to education has remained a pipeline dream for majority of women globally (Suzanne, 2017).

\section{Evidence of Women Empowerment in Kenya}

Women in Kenya have made significant milestones as far as empowerment is concerned. This is due to the fact that a great number of women have been able to access schooling. Education plays a key role in widening the pipeline for women by offering to them critical skills and competencies that are needed for them to break the glass ceiling. This has boosted representation of women in key positions and this has increased their visibility. In the current political scenario in Kenya women have reaped from the affirmative action which gave them a boost as far as empowerment is concerned. Majority of the women who were nominated in last parliament have been able to be elected by their electorates. The implication is that this gave them a spring board which supported them to their success to elective positions. To ensure gender equity and female in management, education systems must act explicitly to eliminate gender bias and discrimination from social cultural attitudes. Kenyan women have performed better in the 2017 elections compared to all other elections since independence in 1963.During the 2017 general election in Kenya, history was made when three women were elected governors, four and a half years after devolution was introduced. These are Charity Ngilu and Ann Waiguruwho won in Kitui and Kirinyaga Counties respectively, with former National Assembly Deputy Speaker Late Joyce Laboso clinching Bomet County. This was a very competitive seat given that the holder of the seat must have a minimum education threshold of a bachelor's degree. The implication is that for a woman to get elective position her visibility must have started earlier than that for the male counterparts. The three elected have an education background which acted as their spring board for them to be visible. It is important to observe that all these women have an education which gave them the confidence and opportunity to compete with their male counterparts. Indeed, this is a wake-up call upon women not to let culture hold them back. A total of three women have been selected in senators. In 2013, no woman was elected. The number of women elected members of county assemblies has also increased from 84 to 96 of the total 1450 . In 
Uganda the women leaders on their part have utilized their newly acquired status and recognition (Oyowa, 2015). The International frameworks and the constitution making in Uganda indeed facilitated women's vibrancy in political leadership. This is indeed an aspect that Kenya can borrow in terms of numerical strength, the increase in numbers of women in formal politics has been progressive. The women have recognized the visibility of the physical presence of women as a critical breakthrough, an initial step of breaking into a domain that was historically not theirs.

There is evidence of women in Kenya overcoming the myriad of obstacles that prevented them from advancing to positions of decision making. This counts as progress for the National Gender and Equality Commission. In order for Kenya to comply with the two third gender rule, several other women were nominated to the respective constitutional offices in order to ensure functionality. Critical to note is that most of the women who were either elected or nominated had the minimum education threshold needed for them to be able to serve in their respective positions. This means that access to education for Kenyan women has gone a long way in eradicating the obstacles that have hindered their full participation to political, social and economic spheres of life.

\section{Barriers to Women Empowerment}

Research has shown that there is a complex set of obstacles, formal and informal, which constrain women's access to higher levels of the education system. These are experiences in the workplace as well as outside. As per Jones (2002), organizational structure restricts the upward mobility of the women. This is because the challenge of work family balance dynamic has deterred many women from occupying senior positions.

Despite all the progress, women leadership is without fault. Similar to their male counterparts, they too engage in misuse of their power and engage in political corruption. In early 2017, we saw the Kenya National Commission on Human Rights seek to block a section of leaders mentioned in integrity cases from vying for elective positions in the 2017 General elections. However, research by Dollar, Fisman and Gatti; Swamy et al. argue that women involved in government are less prone to corruption. Women should be provided more flexibilities in terms of working schedule to balance work-life balance. Women are not excluded from exposure to opportunities of corruption. It is likely that they are disliked especially in top leadership positions since women are less tolerant of corruption and less likely to engage in it compared to men.

\section{Critical Lessons and Way Forward for Countries}

Governments must be active listeners and make sense of women perspectives so that they value their contribution in decision making. Planning contributes hugely for both men and women hold these responsibilities. Government should play a significant role here. Empowering females in the real leadership positions help society to become more gender equitable one. Enforcing actual laws like anti-discrimination will create solution. Across generations, one can see development in construction more family-sensitive work surroundings.

\section{References}

i. Bystydzienski, J. M. (1992). Women Transforming Politics Worldwide Strategies for Empowerment.

ii. Duflo, E. (2012). Women empowerment and economic development. Journal of Economic Literature, 50(4), 10511079.

iii. Fischer, F. (2006). Participatory governance as deliberative empowerment: The cultural politics of discursive space. The American review of public administration, 36(1), 19-40.

iv. Inglehart, R., \& Norris, P. (2003). Rising tide: Gender equality and cultural change around the world. Cambridge University Press.

v. Karl, M. (1995). Women and empowerment: Participation and decision making (Vol. 10). London: Zed Books.

vi. Kabeer, N. (2005). Gender equality and women's empowerment: A critical analysis of the third millennium development goal 1. Gender \& Development, 13(1), 13-24.

vii. Lopez-Claros, A., \&Zahidi, S. (2005). Women's empowerment: measuring the global gender gap. Geneva Switzerland World Economic Forum 2005.

viii. Phipps, A. (2003). Gender and education in the UK: background paper for the UNESCO global monitoring report's Education for all: the leap to equality'. UNESCO.

ix. Robinson, R. (2014). Culture and Legal Policy Punctuation in the Supreme Court's Gender Discrimination Cases. Policy Studies Journal, 42(4), 555-589.

x. Robinson, H. (Ed.). (2015). Feminism Art Theory: An Anthology 1968-2014. John Wiley \& Sons. 